OPEN ACCESS

Edited by:

Robin Mesnage,

King's College London,

United Kingdom

Reviewed by:

Nicolas Defarge,

ETH Zurich, Switzerland

Md. Asaduzzaman,

University of Dhaka, Bangladesh

*Correspondence:

Thomas Bøhn

thomas@genok.org

Specialty section:

This article was submitted to

Environmental Health,

a section of the journal

Frontiers in Environmental Science

Received: 04 May 2017 Accepted: 13 September 2017 Published: 26 September 2017

Citation:

Bøhn T and Lövei GL (2017) Complex

Outcomes from Insect and Weed Control with Transgenic Plants:

Ecological Surprises?

Front. Environ. Sci. 5:60.

doi: 10.3389/fenvs.2017.00060

\section{Complex Outcomes from Insect and Weed Control with Transgenic Plants: Ecological Surprises?}

\author{
Thomas Bøhn ${ }^{1 *}$ and Gabor L. Lövei ${ }^{2,3}$ \\ ${ }^{1}$ GenØk-Centre for Biosafety, Tromsø, Norway, ${ }^{2}$ Department of Agroecology, Flakkebjerg Research Centre, Aarhus \\ University, Slagelse, Denmark, ${ }^{3}$ Institute of Applied Ecology, Fujina Agricultural and Forestry University, Fuzhou, China
}

Agriculture is fundamental for human survival through food production and is performed in ecosystems that, while simplified, still operate along ecological principles and retain complexity. Agricultural plants are thus part of ecological systems, and interact in complex ways with the surrounding terrestrial, soil, and aquatic habitats. We discuss three case studies that demonstrate how agricultural solutions to pest and weed control, if they overlook important ecological and evolutionary factors, cause "surprises": (i) the fast emergence of resistance against the crop-inserted Bt-toxin in South Africa, (ii) the ecological changes generated by Bt-cotton landscapes in China, and (iii) the decline of the monarch butterfly, Danaus plexippus, in North America. The recognition that we work with complex systems is in itself important, as it should limit the belief in reductionist solutions. Agricultural practices lacking eco-evolutionary understanding result in "surprises" like resistance evolution both in weeds and pest insects, risking the reappearance of the "pesticide treadmill" - with increased use of toxic pesticides as the follow-up. We recommend prioritization of research that counteracts the tendencies of reductionist approaches. These may be beneficial on a short term, but with trade-off costs on a medium- to long-term. Such costs include loss of biodiversity, ecosystem services, long-term soil productivity, pollution, and reduced food quality.

Keywords: Bt-toxins, ecology, herbicides/pesticides, glyphosate, GM crops, non-target organisms, resistance evolution

\section{THE USE OF PESTICIDES IN AGRICULTURAL PRACTICE WITH TRANSGENIC PLANTS}

Genetic modifications of crop plants have great potential and promises, but current growing practices are overwhelmingly restricted to four crop species and two kinds of GM modifications. The four species are soybean (Glycine max), maize (Zea mays), oilseed rape (Brassica oleracea), and cotton (Gossypium hirsutum). The majority of these crops (except cotton) are grown on largescale industrial-style farms, mostly in North and South America (James, 2016). The two dominant modifications, herbicide tolerance (HT) and insect resistance (IR), can make crops tolerant to selected herbicides, or toxic to specific groups of herbivorous insects, respectively. Most of the GM soybean and oilseed rape are HT, while transgenic maize and cotton are mostly IR. An increasing number of GM cultivars are "stacked" and/or "pyramided," containing both kinds of modifications, and several constructs. 
HT GM plants open the formerly narrow time window when herbicides could be sprayed on crop fields without risk to the crop itself. Farmers planting HT crops can use herbicides, even at higher concentrations than previously, without damaging their crop. As a result, the global share of the few herbicides that can be used on such GM crops has increased dramatically. The commercially most successful application is linked to herbicides with glyphosate as the active ingredient (Roundup products), whose use only in the USA increased from 3.6 million kg in 1987 to 108 million $\mathrm{kg}$ in 2014 (Myers et al., 2016).

To make cultivated plants toxic to herbivores, the most commonly used method is the insertion of activated toxin genes from the soil-living bacterium Bacillus thuringiensis (Barton et al., 1987). Numerous strains of this bacterium have been isolated, characterized, manipulated and inserted into a variety of crop plants (Bravo et al., 2011), but the majority of fieldgrown insect resistant GM plants are maize and cotton. In the case of maize, the aim was to defend the plant from the attack of two pests that are important in the USA: the nonnative European corn borer Ostrinia nubilalis (Lepidoptera: Pyralidae), and a native beetle, the corn rootworm (Diabrotica virgifera, Coleoptera: Chrysomelidae). In the case of cotton, the primary target pest was the cotton bollworm (Helicoverpa armigera, Lepidoptera: Noctuidae), an important pest in Eurasia, Africa, and the Americas. The presence of the bacterial toxin in the plant defends it from damage by these main pests. After the introduction of Bt-plants a reduction in the amount of insecticides sprayed was observed, especially on cotton, the most intensively insecticide-treated crop plant in the world (Deguine et al., 2008).

GM plants represent an important trajectory of modern agriculture, with a strong focus on weed and insect control. Moreover, in GM plants, whether HT or IR, permit new ways to use pesticides in agriculture. This has interesting practical as well as ecological and evolutionary consequences in comparison to other agricultural practices.

There is an ongoing and rapid change in GM crop plants. In 1996, the first year of commercial planting, GM crop plants predominantly expressed a single transgene of bacterial origins, either a $c r y 1 A b$ Bt gene in IR crops, or a cp4 epsps gene (glyphosate tolerance) in HT plants. Twenty years later, an increasing number of GM crop plants can express up to 6 different Bt-toxins and up to 3 different herbicide tolerance traits (Hilbeck and Otto, 2015; Venter and Bøhn, 2016). We may even expect up to 14 different transgenes in a single GM plant by 2020 (Hakim, 2016). What is the driving force for "stacking" all these traits on top of each other?

In order to forecast the environmental consequences of field-growing GM plants, it is important to stress that genes alone do not determine the outcomes: the gene-organismenvironment ("The Triple Helix") interactions are crucial for the understanding of any biological system (Lewontin, 2000). If we ignore the dynamic responses of nature, "surprises" and failures will be the order of the day. In contrast, by using ecological and evolutionary theory, we would have been able to foresee and possibly avoid many unwanted outcomes that we are experiencing today.
Pesticides are an integral, nearly unavoidable, part of the dominant current agricultural practices. Their dominance can be traced back to the period during and after the Second World War. Problems emerged gradually, and started to be voiced in the early 1960s with the "Silent Spring" of Rachel Carson (Carson, 2002). Since then, pesticides have been under tighter and tighter regulation, and were increasingly recognized as the mixed blessing they are. Notwithstanding the technological advances with pesticides and their applications, the serious global health effects caused by hazardous pesticides has recently made the UN formulate a new set of recommendations. These includes that (i) pesticide use must be closely monitored, regulated and reduced worldwide, and that (ii) non-chemical alternatives must be considered first, e.g., use (agro)ecological methods to naturally supress pests (United Nations, 2017).

In this article, we aim to illustrate the dynamics of ecological/evolutionary responses to field growing of transgenic plants, an important component of modern agriculture. We present three case studies and use these to discuss dynamic ecological and evolutionary responses related to insect and weed control with GM crop plants. Our center of attention concerns the sustainability of this agricultural practice, and whether the ignoring of ecological complexities may lead to new, mistaken technological solutions, resistance evolution and further pesticide use.

\section{CASE STUDY 1. RESISTANCE EVOLUTION IN BUSSEOLA FUSCA TO CRY1AB TOXIN, SOUTH AFRICA}

Several important insect pests of maize are internal feeders, and thus not easy to control by traditional pesticides. This was a strong motive to develop transgenic GM maize lines that can express an insect toxin in planta, thus presenting the potential to control such internal feeders. In South Africa, the main target insect pest, Busseola fusca (Lepidoptera: Noctuidae), is such a pest, whose larvae are boring inside the maize plant. They were successfully controlled by Bt-maize expressing the Cry1 Ab-toxin (MON810) after its introduction in 1998, for a period of about 6 years. In the 2004/5 season, the first reports on resistant insects were coming in: $B$. fusca larvae could be found feeding on Bt maize plants (van Rensburg, 2007; Figure 1A). By 2010, the area where such resistant insects were found increased to cover most of the maize growing areas in the country (Kruger et al., 2012; Van den Berg et al., 2013). Where resistant insects appeared, farmers responded by re-starting the previous practice of spraying insecticides-now on the transgenic MON810 variety (Figure 1B).

This resistance evolution of $B$. fusca in South Africa triggered the replacement of the original, single toxin-expressing MON810 with MON89034, a plant that expresses two toxins: Cry1A.105 and Cry2Ab2 (Van den Berg et al., 2013). Thus, the emerging resistance in pest insects led to the stacking of two insect toxins in the same plant. This may resemble the start of the "pesticide treadmill," where the typical response to emerging resistance to an insecticide was to start using cocktails of various ones, with 


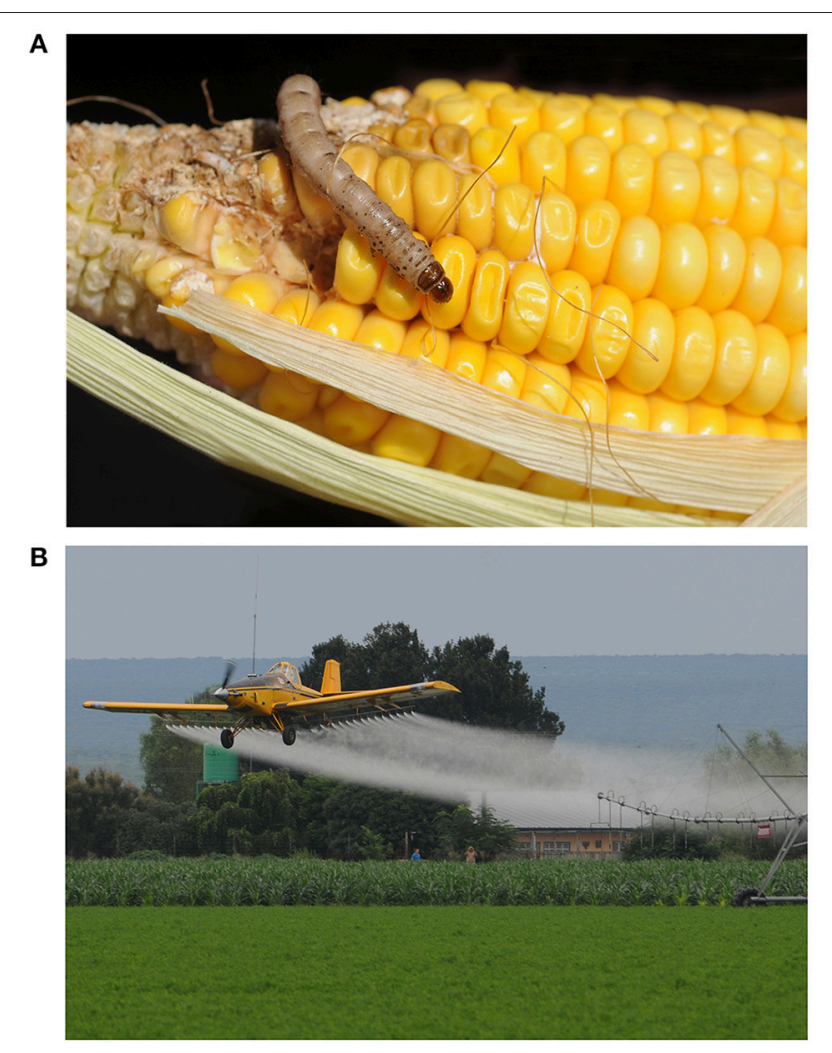

FIGURE 1 | Resistance development to Cry1Ab in South Africa. After the development of resistance to Bt, the larvae of the target pest, Busseola fusca, could be observed in the field, feeding on MON810 maize cobs (A). The response from the farmers was to spray insecticides, paid by Monsanto, on the "insect resistant" MON810 Bt-maize plants to reduce yield losses (B). Photos taken in the Vaalharts region in 2012 by Thomas Bøhn.

the argument that these combinations will remain effective for longer (Nicholls and Altieri, 1997). For sprayed pesticides, this has not been a sustainable solution, because multiple resistances emerged, making the problem more severe.

\section{CASE STUDY 2. HELICOVERPA ARMIGERA REPLACED BY MIRID BUGS AS MAJOR PESTS, CHINA}

China is among the biggest cotton producers of the world. On five of the six major cotton-growing regions, mostly smallholders grow cotton, using it as a cash crop. Before 1997, the use of pesticides to control insect pests, the cotton bollworm $H$. armigera in particular, was very high and included $14-28$ treatments per season (Pemsl and Waibel, 2007). Resistance was widespread, and the increased frequency of sprayings did not provide a lasting solution, even if the serious human safety issues are disregarded. The introduction of Bt-cotton after a government decision in 1996 resulted in quick take-up of the technology, and improved the conditions for the farmers considerably. Not only was there a decline in pest attacks on cotton, especially in the early season; other important crops harmed by the polyphagous $H$. armigera also started to show reduced pest densities ( $\mathrm{Wu}$ et al., 2008). The reason was that the typically small cotton fields were dispersed in the landscape and cotton, the previously preferred crop for $H$. armigera, was replaced by Bt-cotton and suddenly became unusable as a habitat for that insect species. The efficient killing of the target pest had turned cotton plots into a population sink at the regional/landscape level (Lu et al., 2010). This shows the potential dynamics in source and sink populations, i.e., conditional sources and sinks (Loreau et al., 2013), altered by context dependent conditions, here the introduction of Bt-toxin in cotton, and the particular distribution of cotton plots in the overall cultivated landscape.

Had the story ended here, it would have been a great success story of the Bt-cotton (Wu et al., 2008). The fact that Bt-cotton led to a regional decline in a major pest species and therefore also diminished the damage caused by $H$. armigera on multiple crop plants also coincided with a reduced load of toxic pesticides (Pemsl and Waibel, 2007).

However, due to ecological responses and interactions, the full story is more interesting. As Bt-cotton became less suitable to $H$. armigera, large resources, both in terms of pesticide-free habitat and cotton plant biomass became available to species less susceptible to Bt-toxins. Additionally, the reduced pesticide pressure also, at least initially (Carrière et al., 2016), eased the pesticide pressure on other insect groups. A formerly secondary pest group, mirid bugs (Miridae, Heteroptera) now increased in numbers, and became an important pest on cotton ( $\mathrm{Lu}$ et al., 2010). With the high densities of mirids on Bt-cotton, these plots now became population sources of mirids that subsequently migrated to other crops. The outcome was that the higher proportion of cotton was Bt-transgenic in the landscape, the higher became the densities of mirids on other crops in the region ( $\mathrm{Lu}$ and $\mathrm{Wu}, 2011$ ). Thus, the management regime of Btcotton, including the change in pesticide use triggered by the use of the GM cultivars, made the same cotton patches sources of another herbivorous pest, and caused the subsequent spread of a non-target, secondary pest at the landscape level (Lu et al., 2010).

Case study 2 illustrates how the single-species focus can backfire when a "technological solution" is employed against a single species, and ecological complexity gets ignored. Crops usually have numerous target pests, or potential target pests, some of which may be minor due to various reasons; this does not mean that they do not have the potential to cause large damagetheir damage potential is only suppressed by the dominating pest species. Change the density of this major pest, and these other potential pests may quickly respond due to competitive release (Zeilinger et al., 2016).

\section{CASE STUDY 3. THE MONARCH BUTTERFLY AND LANDSCAPE LEVEL EFFECTS OF HERBICIDE USE, NORTH AMERICA}

One of the most fascinating insect migrations is performed by the North American monarch butterfly, Danaus plexippus 
(Lepidoptera: Danaidae), that migrates from its summer distribution area, covering a large part of North America, to winter in a small part of central Mexico, in spectacular masses (Stenoien et al., 2016). For this reason, as well as for its spectacular coloration, the monarch has become a symbol of beauty and freedom-one of the conservation icons of North America. The monarch larvae feed on milkweed, Asclepias syriaca, which is a common weed, especially in maize and soybeans fields (Oberhauser et al., 2001). In 1999, an article in Nature reported that the larvae of the monarch butterfly suffered high mortality in laboratory trials where they fed on milkweed leaves dusted with a high density of transgenic Btmaize pollen (Losey et al., 1999). This study generated heated discussions, but also triggered a large research project examining the possible consequences of planting transgenic maize over vast areas in the summer distribution range of the monarch butterfly. The summary conclusion was that the risk of being exposed to significant amounts of Bt-toxin from maize plants through pollen in the field was negligible (Sears et al., 2001). However, Oberhauser and co-workers cautioned that the issue needed to be looked at from a larger perspective, including weed control and the use of pesticides by farmers (Oberhauser et al., 2001).

By the mid-2010s it became obvious that the cautions were justified: the monarch population densities were dramatically reduced with a loss of an estimated 40 million individual butterflies per year (about 9\% decline per year) after 1993/1994 (Williams and Brower, 2016; Oberhauser et al., 2017). The lowest recordings of the monarch densities on the wintering ground are from 2013 to 2015 (Rendón-Salinas and Tavera-Alonso, 2015), and the probability that the fascinating migration of the eastern monarch will go extinct within 20 years is estimated to be 11$57 \%$ (Semmens et al., 2016). Alarmed by these perspectives, initiatives across borders (US, Mexico, Canada) have been started to conserve the monarch butterfly. However, management action needs an understanding of the causes of the decline in order to improve the situation. So what are the key causal factors to explain the monarch decline?

The exponential growth of hectares with GM plants after 1996 in the US increased the acreage under Bt-transgenic plants, but even more those of glyphosate tolerant GM plants. From 2004 and until 2015, plants with "stacked" traits, i.e., both with Bttoxins and herbicide tolerance increased from $<10$ million ha to about 60 million ha (James, 2015). As a result, non-target organisms including monarchs would interact, not only with Bttoxins and herbicides directly, but also with the indirect effects of these factors at a landscape level.

A subtle but highly important indirect effect on the landscape level is related to herbicide tolerant GM crops and the massive use of broad-spectrum herbicides. The increased use of glyphosate products have caused a dramatic decline in the dominant host plant for the monarch. This is, seen from the monarch point of view, a serious habitat destruction of its highly specialized habitat. What is efficient weed management for the farmers can be fatal for a butterfly depending on a dominant host plant that grows between the rows of HT GM plants.

Monarch butterflies have experienced a dramatic decline in the availability of their host plant, the milkweed. In Iowa, milkweed was present in $51 \%$ of the fields in 1999, but only in $8 \%$ a decade later. In addition, even in the fields where still observed, milkweed density was reduced to about $10 \%$ of its original value (Hartzler, 2010). In sum, the decline in milkweed amounted to a near-complete elimination in the core of the breeding range of the monarchs (Pleasants, 2015). The maize and soybean fields were turned into milkweed deserts.

At the landscape level over the whole mid-western USA, the decline in milkweed has been almost $40 \%$. However, since the monarch butterflies on average lay 3.9 times more eggs on milkweed stems in agricultural fields, where the reduction of milkweed is most severe, the capacity to support the monarch as a species is reduced by $71 \%$ (Pleasants, 2017).

The threat to the monarch triggered various conservation responses, including a restoration goal of reaching "six ha of overwintering monarchs" (i.e., six ha of trees covered by monarchs). To succeed, 1.6 billion additional milkweed plants would be needed, a number higher than the estimated current total population (1.34 billion plants) for the whole Midwest (Pleasants, 2017). Restoration of the milkweed seems to be crucial and the use of HT GM plants is identified as a key for the milkweed decline (Pleasants and Oberhauser, 2013; Zalucki et al., 2016).

\section{DISCUSSION}

The three case studies described above exemplify that agricultural ecosystems, even if arguably simplified, retain complexity, and that solutions to agricultural problems should be scrutinized from an ecological point of view. Ignoring ecological interactions tends to undermine the overly simple solutions, here exemplified with insect and weed control by the dominating GM plant traits and associated technology. When a pest insect or weed species overcomes a suggested "solution" to hold their density low, strong selective advantages will play out. Under such conditions, natural selection may be effective in a timespan of a few years, and threaten to undermine the efficiency of our weed and insect control, and thus also the goal of improved agricultural productivity.

When we look at the dominant technologies currently accompanying GM plants, there are particular challenges related to resistance evolution, both for herbicide tolerance traits and for insect resistance.

\section{Herbicide Tolerant Crops and Weed Resistance Evolution}

From 1995 to 2014, the global agricultural use of glyphosate rose 14.6-fold, from 51 million $\mathrm{kg}$ to 747 million $\mathrm{kg}$ and HT GM crops have been a major driver for this change. Moreover, by 2016, about 56\% of the global use of glyphosate was connected to HT GM crops (Benbrook, 2016). Specific for the HT GM plants is that herbicides can be sprayed in higher doses and repeatedly during the growth season of the plants. The vast "experiment" that was initiated with HT GM crops and glyphosate as a stand-alone herbicide on millions of hectares of cropland, imparted tremendous selection pressure on the 
weed populations. This has been a key factor for the resistance evolution, now documented for 37 species of weeds globally. Such development may lead to the familiar "treadmill" where resistance triggers more applications/higher doses, which leads to stronger selection pressure for resistance, etc. and eventually the use of additional herbicides like atrazine and 2,4D (Binimelis et al., 2009).

Unfortunately, the glyphosate resistant crops were not integrated into a total weed management program, rather it replaced all of the other programs (Shaner et al., 2012). In hindsight, this was not a wise move and showed us that no herbicide is invulnerable to resistance. At least three different mechanisms of resistance is identified: (i) alteration of the target site; (ii) changes in sequestration and/or translocation of the herbicide, and (iii) changes in the rates of metabolism of the herbicide (reviewed in Shaner et al., 2012).

For the farmers, resistant weeds are a difficult practical obstacle to handle. Although farmers often have a longterm perspective on their farming activity, they may also be attracted to quick-fix solutions, including pesticides and growing monocultures. Unfortunately, crop and herbicide monocultures create conditions for resistance development (Beckie, 2011).

The magnitude of resistance problems should be incentive enough to further explore the plurality of methods that can be used under integrated pest management, not only to delay resistance but to promote alternative and preferably nontoxic pest control systems (United Nations, 2017). Chemical treatments, coupled with the unavoidable resistance development are major blocking factors to a sustainable agriculture.

The use of herbicides like glyphosate also has the potential to affect ecosystem, animal and human health. The massive use of glyphosate, totaling 852 million kg globally by 2014 (Benbrook, 2016), which directly or indirectly will expose non-target biodiversity in terrestrial, soil and aquatic communities (Venter and Bøhn, 2016), represent a major source of environmental pollution. In addition, glyphosate is shown to accumulate in (i) soils that have a history of glyphosate use (Duke et al., 2017), and (ii) in HT soybeans (Bøhn et al., 2014), more when the plant is sprayed later in the season (Duke et al., 2003). This will bring glyphosate residues into the global food and feed chains (Bøhn et al., 2014).

The increased awareness of glyphosate toxicity, coupled with the increased volume used, should lead to stronger restrictions, for example lower acceptance level for glyphosate residues in food and feed (Cuhra et al., 2016). In this context it is perplexing why the maximum residue level (MRL) for glyphosate was raised 200 -fold from 0.1 to $20 \mathrm{mg} / \mathrm{kg}$ in Europe, and to $40 \mathrm{mg} / \mathrm{kg}$ in the US (Cuhra, 2015). This set of events has been termed "The Glyphosate Paradox" (Cuhra et al., 2016). The WHO/IARC categorization of glyphosate as probably carcinogenic to humans (Guyton et al., 2015), although disputed by EFSA (EFSA, 2015), is underlining the significance of the controversy around the glyphosate-based herbicides.

Glyphosate is now also implicated in the decline of the monarch butterfly (Stenoien et al., 2016), further illustrating the various kinds of environmental damage that reliance on a few plant protection chemicals may bring. However, the monarch may not be the only species at risk for similar reasons-a total of 39 protected European lepidopteran species have maize weeds in their host plant range (Lövei et al., 2016).

\section{Insect Resistant Crops and Resistance Evolution}

GMO related "internal" pesticides such as Bt-toxins have a particular problem related to resistance evolution. The GM plants express Bt-toxins continuously, also when the "pests" are not a problem due to their low density. Pesticides expressed continuously, as in current insect resistant crops, simply raises the bar and offers continuous "trial and error testing" within potential pest populations, with a huge fitness reward on individuals that acquire resistance.

That evolution will eventually result in resistance developing in the target pest populations was foreseen before Bt-transgenic plants were grown commercially, and different strategies have been suggested and adopted to delay undesirable pest adaptation. For transgenic Bt- plants, the high-dose/refugia strategy is the most frequently recommended (Carrière et al., 2016). The role of the non-GM refugia is to secure the reproduction of susceptible insects and assure that the genes that make the target sensitive to the Bt-toxin do not disappear from the population. Thus, the high-dose Bt should remain effective, killing insects that have resistance alleles from one of the parents, and keeping the target population heterozygous.

The South African case with B. fusca showed that farmers initially did not follow the recommendation; only $8 \%$ of them established a refuge. By 2008, however, most or all farmers had established refugia (Kruger et al., 2009). This may have been too late, it seems likely that the initial non-compliance played a role in the fast appearance of the resistance (Van den Berg, 2016). The other key factor in promoting field-evolved resistance to Bt-toxin is that the high-dose standard is not met. The Cryl Ab maize used in South Africa in the relevant period did not fulfill this criteria for B. fusca (Van den Berg, 2016). Finally, the hypothesis of functionally recessive inheritance of resistance in the insect, meaning that when resistant and susceptible parents mate, the offspring will be susceptible, was rejected by experimental data in the South African B. fusca (Campagne et al., 2013).

The $B$. fusca case illustrates that the positive effect of reduced amounts of insecticides sprayed (e.g., Marvier et al., 2007; Osteen and Fernandez-Cornejo, 2013) may not last, or lead to the use of stacked events with multiple Cry toxins inserted. A recent review (Carrière et al., 2016) concluded that under the current way of growing, the pyramiding of Bt-toxins is not a stand-alone solution to the resistance development problem.

Another reason for pyramiding different Cry toxins in the same plant is to protect the plant from pest insects from different taxonomic groups, e.g., from both Lepidoptera (Cry1 and Cry2 toxins) and Coleoptera (Cry3 toxins). In maize, up to six different Cry toxins are combined in the same plant, as in hybrid MON $89034 \times 1507 \times$ MON $88017 \times 59122$, from Monsanto and Dow AgroSciences, which expresses cry1A.105, cry $1 \mathrm{~F}$, cry2 Ab2, cry3Bb1-, cry34Ab1, and cry35Ab1. Clearly, the added range of targeted pests is likely to produce stronger effects on non-target communities as well (Then, 2009). 
When two toxins are active against the same insect species, resistance may be delayed. In North Carolina, transgenic cotton with two Cry-toxins resulted in much higher mortality (96 vs. $44 \%$ ) in the pest Helicoverpa zea compared to cotton with a single Cry-toxin (Carrière et al., 2016). At the same time, using several toxins at the same time is analogous to the use of multiple antibiotics in the same treatment. The risk is that fewer agents are left unused when resistance appears. In a long-term perspective, resistance will inevitably develop, even if a range of pest management practices will delay the process. Reliance on pesticides, does not represent a sustainable agricultural practice. Therefore, the UN is recommending (i) proactive measures to reduce or eliminate harmful pesticides, and (ii) to consider nonchemical alternatives first (United Nations, 2017).

The risk that control measures against target pest insects are lost due to resistance evolution can be tracked back more than 100 years, and is particularly relevant if there is a continuous selection pressure for resistance (Andow, 2008). Nevertheless, most pest populations have remained susceptible to Bt toxins, but 5 out of 13 major pest species have already acquired field-based resistance (reviewed in Tabashnik et al., 2013).

A pesticide could best solve a pest problem if it was perfectly specific for the target species, and killed only that harmful organism. In that case, effects on other species would be limited to the altered ecological interactions in the ecosystem, most plausibly on species directly linked to the target species in the food web. However, known chemical and biological pesticides are either very broad, harming all insects with an exoskeleton (as for DDT), or are more specific because their action requires certain conditions (like high $\mathrm{pH}$, cleavage by enzymes, etc. as with Bt-toxins). This may limit the range of species/taxa harmed, although there still may be several species in the harmed group. For example, the order Lepidoptera, the main target group of Cry1 and Cry2 toxins, contains 126 families and some 180,000 known species (Capinera, 2008). Moreover, a single plant species may be a host to numerous species. Maize and cotton are registered as hosts for 776 and 872 lepidopteran species, respectively (Robinson et al., 2010).

When the criteria of specificity to the pest species is not fulfilled, harmful effects on non-target species (biodiversity) can be expected. A range of factors contributes to potential negative effects on non-target species.

Firstly, the toxicity of the pesticides will be crucial, which is typically taxa/species/age- and context- dependent.

Secondly, the break-down rate will modify and reduce the toxicity over time. Pesticides that are decaying slowly may accumulate in the food web and have serious long-term effects, such as the PCBs (Gobas et al., 2016). Pesticides that do not break down may be a part of the food or feed produced and have further effects on humans or animals along the food/feed chain. The break-down rate of chemicals depends on environmental factors like $\mathrm{pH}$, soil type, binding to other particles etc., which adds to the complexity.

Thirdly, the timing and dosage of applications are important for potential unwanted effects. Treatments with toxic pesticides are ideally precisely timed to hit when the problem is severe. The option to time the application of a pesticide can therefore be a good thing. With pesticides that are expressed continuously from the plant genome, as in Bt-plants, such flexibility is lost.

In the context of negative effects on biodiversity, the sensitivity of non-target organisms, most of the species in soil and aquatic communities have never been tested for their vulnerability to Bttoxins. Several aspects of the fate of Bt-toxins are not well-known, including amounts, break-down rates and effects. Further, studies of tri-trophic relationships and food web interactions may provide insight to community responses (Yu et al., 2014).

\section{Can Stacked Traits Act as Multiple Stressors?}

The understanding of resistance evolution and stacking/pyramiding of traits must be linked to potential combinatorial effects on non-target organisms. The use of stacked events represents: (i) increased doses/more applications of herbicides per season, and (ii) a broader range of Cry toxins in insect resistant GM plants. Both these effects trigger positive feedback loops with stronger selection pressures and further resistance evolution. Since these toxins/chemicals/traits will meet and interact, also with other stressors in the environment, the co-exposure and potential combinatorial effects need to be studied (Nørgaard and Cedergreen, 2010; Bjergager et al., 2011). Combinatorial effects between Bt-toxins and herbicides may enhance toxicity (Then and Bauer-Panskus, 2017). For example, Bøhn and co-workers showed that CrylAb and Cry2Aa toxins act in combination (additively), indicating that "stacked events" may increase negative effects on non-target organisms (Bøhn et al., 2016). However, combinatorial effects represents a major knowledge gap in the scientific literature (Venter and Bøhn, 2016).

\section{Sustainability of Agriculture}

Agriculture has been fundamental for the rise of human civilization (Diamond, 1999) and continues to be vital for human survival through food production. However, many modern agricultural innovations relied on non-renewable resources that are not sustainable (Gliessman, 2015). We need a strong prioritization of resources for research to build knowledge to ensure that future food production is sustainable. In particular, there is a need to counteract agricultural practices that are beneficial on a short term, but with trade-off costs on a medium to long term scale. Such costs includes loss of biodiversity, ecosystem services, soil productivity, pollution and reduced food quality.

\section{CONCLUSIONS}

The currently dominant agricultural practice has changed the natural spatial distributions of plant species that provide food, fiber, and other important resources for us (classified as provisioning ecosystem services), and resulted in habitats that are less diverse than the original habitats that were converted to croplands. Nonetheless, these are biological entities, supporting and interacting with various plant, animal, fungal, and microbial communities in complex ways. The recognition that when trying to manage agricultural fields and landscapes, 
we work with a complex biological system is in itself important, as adopting this view should limit the belief in reductionist solutions.

Moreover, from an evolutionary perspective on sustainable food production, chemical pesticides, both insecticides such as Bt-toxins and sprayed herbicides, carry problems that are hard to solve. Dominant technologies in transgenic plants rely on new ways of using pesticides. These practices does not utilize and often contradicts ecological understanding and are therefore likely to exacerbate current problems. It is not likely that pesticides can be eliminated from our dominant agricultural practices in the near future. Key factors to uphold or improve their efficiency would be to increase the precision (specificity, timing) while minimizing the amount used. This would reduce pollution, lower their accumulation in the environment as well as in food, both of which are positive outcomes for ecosystem and human health. We also have to place the analysis of possible environmental consequences into an agroecological context, because that approach inherently considers the possibility of multiple stressor interaction, sublethal effects, non-linear, and synergistic outcomes that are so characteristic of biological systems. The

\section{REFERENCES}

Andow, D. A. (2008). The risk of resistance evolution in insects to transgenic insecticidal crops. Collect. Biosaf. Rev. 4, 142-199. Available online at: http:// www.icgeb.org/biosafety/publications/collections.html

Barton, K. A., Whiteley, H., and Yang, N.-S. (1987). Bacillus thuringiensis $\$$ Endotoxin expressed in transgenic Nicotiana tabacum provides resistance to lepidopteran insects. Plant Physiol. 85, 1103-1109. doi: 10.1104/pp.85.4.1103

Beckie, H. J. (2011). Herbicide-resistant weed management: focus on glyphosate. Pest Manag. Sci. 67, 1037-1048. doi: 10.1002/ps.2195

Benbrook, C. M. (2016). Trends in glyphosate herbicide use in the United States and globally. Environ. Sci. Eur. 28:3. doi: 10.1186/s12302-016-0070-0

Binimelis, R., Pengue, W., and Monterroso, I. (2009). "Transgenic treadmill": responses to the emergence and spread of glyphosate-resistant johnsongrass in Argentina. Geoforum 40, 623-633. doi: 10.1016/j.geoforum.2009.03.009

Bjergager, M. B., Hanson, M. L., Lissemore, L., Henriquez, N., Solomon, K. R., and Cedergreen, N. (2011). Synergy in microcosms with environmentally realistic concentrations of prochloraz and esfenvalerate. Aquat. Toxicol. 101, 412-422. doi: 10.1016/j.aquatox.2010.11.004

Bøhn, T., Cuhra, M., Traavik, T., Sanden, M., Fagan, J., and Primicerio, R. (2014). Compositional differences in soybeans on the market: glyphosate accumulates in roundup ready GM soybeans. Food Chem. 153, 207-215. doi: 10.1016/j.foodchem.2013.12.054

Bøhn, T., Rover, C. M., and Semenchuk, P. R. (2016). Daphnia magna negatively affected by chronic exposure to purified Cry-toxins. Food Chem. Toxicol. 91, 130-140. doi: 10.1016/j.fct.2016.03.009

Bravo, A., Likitvivatanavong, S., Gill, S. S., and Soberón, M. (2011). Bacillus thuringiensis: a story of a successful bioinsecticide. Insect Biochem. Mol. Biol. 41, 423-431. doi: 10.1016/j.ibmb.2011.02.006

Campagne, P., Kruger, M., Pasquet, R., Le Ru, B., and Van den Berg, J. (2013). Dominant inheritance of field-evolved resistance to bt corn in Busseola fusca. PLoS ONE 8:e69675. doi: 10.1371/journal.pone.0069675

Capinera, J. L. (2008). Encyclopedia of Entomology. Dordrecht: Springer Science+Business Media B.V.

Carrière, Y., Fabrick, J. A., and Tabashnik, B. E. (2016). "Advances in managing pest resistance to Bt crops: pyramids and seed mixtures," in Advances in Insect Control and Resistance Management (Berlin: Springer), 263-286.

Carson, R. (2002). Silent Spring. Boston, MA: Houghton Mifflin. examples discussed in this article also underline the importance to incorporate landscape-level ecological knowledge into the evaluation practice, because spatially explicit analysis of potential impacts are important tools in making agricultural practice more sustainable.

In the three case studies discussed, the GM plants associated with simple pesticide-solutions were unable to solve complex agricultural problems. We argue that the resulting resistance development and increased use of herbicides arose because basic ecological and evolutionary theory was overlooked. Had such knowledge been included, we would have foreseen and possibly been able to avoid some of the unwanted outcomes we are experiencing today.

\section{AUTHOR CONTRIBUTIONS}

TB and GL conceived the study and wrote the paper.

\section{FUNDING}

The study was funded by GenØk-Centre for Biosafety, Fujian Agriculture and Forestry University, and Aarhus University.

Cuhra, M. (2015). Review of GMO safety assessment studies: glyphosate residues in roundup ready crops is an ignored issue. Environ. Sci. Eur. 27, 1-14. doi: 10.1186/s12302-015-0052-7

Cuhra, M., Bøhn, T., and Cuhra, P. (2016). Glyphosate: too much of a good thing? Front. Environ. Sci. 4:28. doi: 10.3389/fenvs.2016.00028

Deguine, J.-P., Ferron, P., and Russell, D. (2008). Sustainable pest management for cotton production. A review. Agron. Sustain. Dev. 28, 113-137. doi: 10.1051/agro:2007042

Diamond, J. M. (1999). Guns, Germs, and Steel: The Fates of Human Societies. New York, NY: Norton.

Duke, S. O., Rimando, A. M., Pace, P. F., Reddy, K. N., and Smeda, R. J. (2003). Isoflavone, glyphosate, and aminomethylphosphonic acid levels in seeds of glyphosate-treated, glyphosate-resistant soybean. J. Agric. Food Chem. 51, 340-344. doi: 10.1021/jf02 $5908 \mathrm{i}$

Duke, S. O., Rimando, A. M., Reddy, K. N., Cizdziel, J. V., Bellaloui, N., Shaw, D. R., et al. (2017). Lack of transgene and glyphosate effects on yield, and mineral and amino acid content of glyphosate-resistant soybean: glyphosate effects on glyphosate-resistant soybean. Pest Manag. Sci. doi: 10.1002/ps.4625. [Epub ahead of print].

EFSA (2015). Conclusion on the peer review of the pesticide risk assessment of the active substance glyphosate. EFSA J. 13:4302. doi: 10.2903/j.efsa.2015.4302

Guyton, K. Z., Loomis, D., Grosse, Y., El Ghissassi, F., BenbrahimTallaa, L., Guha, N., et al. (2015). Carcinogenicity of tetrachlorvinphos, parathion, malathion, diazinon, and glyphosate. Lancet Oncol. 16, 490-491. doi: 10.1016/S1470-2045(15)70134-8

Gliessman, S. R. (2015). Agroecology: the Ecology of Sustainable Food Systems. Boca Raton, FL: CRC Press/Taylor \& Francis Group.

Gobas, F. A., Burkhard, L. P., Doucette, W. J., Sappington, K. G., Verbruggen, E. M., Hope, B. K., et al. (2016). Review of existing terrestrial bioaccumulation models and terrestrial bioaccumulation modeling needs for organic chemicals. Integr. Environ. Assess. Manag. 12, 123-134. doi: 10.1002/ ieam. 1690

Hakim, D. (2016). Doubts about the promised bounty of genetically modified crops. N. Y. Times.

Hartzler, R. G. (2010). Reduction in common milkweed (Asclepias syriaca) occurrence in Iowa cropland from 1999 to 2009. Crop Prot. 29, 1542-1544. doi: 10.1016/j.cropro.2010.07.018 
Hilbeck, A., and Otto, M. (2015). Specificity and combinatorial effects of Bacillus thuringiensis Cry toxins in the context of GMO environmental risk assessment. Front. Environ. Sci. 3:71. doi: 10.3389/fenvs.2015.00071

James, C. (2015). Global Status of Commercialized Biotech/GM Crops: 2015. Ithaca, NY: ISAAA.

James, C. (2016). Global Status of Commercialized Biotech/GM Crops: 2016. Ithaca, NY: ISAAA.

Kruger, M., Van Rensburg, J. B. J., and Van den Berg, J. (2009). Perspective on the development of stem borer resistance to Bt maize and refuge compliance at the Vaalharts irrigation scheme in South Africa. Crop Prot. 28, 684-689. doi: 10.1016/j.cropro.2009.04.001

Kruger, M., Van Rensburg, J. B. J., and Van den Berg, J. (2012). Transgenic Bt maize: farmers' perceptions, refuge compliance and reports of stem borer resistance in South Africa. J. Appl. Entomol. 136, 38-50. doi: 10.1111/j.1439-0418.2011.01616.x

Lewontin, R. C. (2000). The Triple Helix - Gene, Organism and Environment. Cambridge, MA: Harvard University Press.

Loreau, M., Daufresne, T., Gonzalez, A., Gravel, D., Guichard, F., Leroux, S. J., et al. (2013). Unifying sources and sinks in ecology and Earth sciences. Biol. Rev. 88, 365-379. doi: 10.1111/brv.12003

Losey, J. E., Rayor, L. S., and Carter, M. E. (1999). Transgenic pollen harms monarch larvae. Nature 399, 214-214. doi: 10.1038/20338

Lövei, G. L., Holst, N., and Lang, A. (2016). "Can the growing of transgenic maize threaten protected Lepidoptera in Europe?” in: Dutch Butterfly Conservation 2016/Future 4 butterflies in Europe (Wageningen), 39. Book of Abstracts.

$\mathrm{Lu}, \mathrm{Y}$., and $\mathrm{Wu}, \mathrm{K}$. (2011). Mirid bugs in china: pest status and management strategies. Outlooks Pest Manag. 22, 248-252. doi: 10.1564/22dec02

Lu, Y., Wu, K., Jiang, Y., Xia, B., Li, P., Feng, H., et al. (2010). Mirid bug outbreaks in multiple crops correlated with wide-scale adoption of Bt cotton in China. Science 328, 1151-1154. doi: 10.1126/science.1187881

Marvier, M., McCreedy, C., Regetz, J., and Kareiva, P. (2007). A meta-analysis of effects of bt cotton and maize on nontarget invertebrates. Science 316, 1475-1477. doi: 10.1126/science. 1139208

Myers, J. P., Antoniou, M. N., Blumberg, B., Carroll, L., Colborn, T., Everett, L. G., et al. (2016). Concerns over use of glyphosate-based herbicides and risks associated with exposures: a consensus statement. Environ. Health 15:19. doi: 10.1186/s12940-016-0117-0

Nicholls, C. I., and Altieri, M. A. (1997). Conventional agricultural development models and the persistence of the pesticide treadmill in Latin America. Int. J. Sustain. Dev. World Ecol. 4, 93-111. doi: 10.1080/13504509709469946

Nørgaard, K. B., and Cedergreen, N. (2010). Pesticide cocktails can interact synergistically on aquatic crustaceans. Environ. Sci. Pollut. Res. 17, 957-967. doi: 10.1007/s11356-009-0284-4

Oberhauser, K. S., Prysby, M. D., Mattila, H. R., Stanley-Horn, D. E., Sears, M. K., Dively, G., et al. (2001). Temporal and spatial overlap between monarch larvae and corn pollen. Proc. Natl. Acad. Sci. U.S.A. 98, 11913-11918. doi: 10.1073/pnas.211234298

Oberhauser, K., Wiederholt, R., Diffendorfer, J. E., Semmens, D., Ries, L., Thogmartin, W. E., et al. (2017). A trans-national monarch butterfly population model and implications for regional conservation priorities. Ecol. Entomol. 42, 51-60. doi: 10.1111/een.12351

Osteen, C. D., and Fernandez-Cornejo, J. (2013). Economic and policy issues of US agricultural pesticide use trends. Pest Manag. Sci. 69, 1001-1025. doi: 10.1002/ps.3529

Pemsl, D., and Waibel, H. (2007). Assessing the profitability of different crop protection strategies in cotton: case study results from Shandong Province, China. Agric. Syst. 95, 28-36. doi: 10.1016/j.agsy.2007. 02.013

Pleasants, J. (2017). Milkweed restoration in the Midwest for monarch butterfly recovery: estimates of milkweeds lost, milkweeds remaining and milkweeds that must be added to increase the monarch population. Insect Conserv. Divers. 10, 42-53. doi: 10.1111/icad.12198

Pleasants, J. M. (2015). "Monarch butterflies and agriculture," in Monarchs in a Changing World: Biology and Conservation of an Iconic Insect, eds K. S. Oberhauser, S. Altizer, and K. R. Nail (Ithaca, NY: Cornell University Press), 169-178.

Pleasants, J. M., and Oberhauser, K. S. (2013). Milkweed loss in agricultural fields because of herbicide use: effect on the monarch butterfly population: herbicide use and monarch butterflies. Insect Conserv. Divers. 6, 135-144. doi: 10.1111/j.1752-4598.2012.00196.x
Rendón-Salinas, E., and Tavera-Alonso, G. (2015). Forest Surface Occupied by Monarch Butterfly Hibernation Colonies in December 2015. WWF-Mexico, DF. Robinson, G. S., Ackery, P. R., Kitching, I. J., Beccaloni, G. W., and Hernández, L. M. (2010). HOSTS - A Database of the World's Lepidopteran Hostplants. London: Natural History Museum. Available online at: http://www.nhm.ac.uk/ hosts (Accessed August 18, 2017).

Sears, M. K., Hellmich, R. L., Stanley-Horn, D. E., Oberhauser, K. S., Pleasants, J. M., Mattila, H. R., et al. (2001). Impact of Bt corn pollen on monarch butterfly populations: a risk assessment. Proc. Natl. Acad. Sci. U.S.A. 98, 11937-11942. doi: 10.1073/pnas.211329998

Semmens, B. X., Semmens, D. J., Thogmartin, W. E., Wiederholt, R., LópezHoffman, L., Diffendorfer, J. E., et al. (2016). Quasi-extinction risk and population targets for the Eastern, migratory population of monarch butterflies (Danaus plexippus). Sci. Rep. 6:23265. doi: 10.1038/srep23265

Shaner, D. L., Lindenmeyer, R. B., and Ostlie, M. H. (2012). What have the mechanisms of resistance to glyphosate taught us? Pest Manag. Sci. 68, 3-9. doi: 10.1002/ps.2261

Stenoien, C., Nail, K. R., Zalucki, J. M., Parry, H., Oberhauser, K. S., and Zalucki, M. P. (2016). Monarchs in decline: a collateral landscape-level effect of modern agriculture: landscape-level effect of GM crops on monarchs. Insect Sci. doi: 10.1111/1744-7917.12404. [Epub ahead of print].

Tabashnik, B. E., Brévault, T., and Carrière, Y. (2013). Insect resistance to Bt crops: lessons from the first billion acres. Nat. Biotechnol. 31, 510-521. doi: $10.1038 /$ nbt.2597

Then, C. (2009). Risk assessment of toxins derived from Bacillus thuringiensissynergism, efficacy, and selectivity. Environ. Sci. Pollut. Res. 17, 791-797. doi: 10.1007/s11356-009-0208-3

Then, C., and Bauer-Panskus, A. (2017). Possible health impacts of Bt toxins and residues from spraying with complementary herbicides in genetically engineered soybeans and risk assessment as performed by the European Food Safety Authority EFSA. Environ. Sci. Eur. 29, 1-11. doi: 10.1186/s12302-016-0099-0

United Nations (2017). Report of the Special Rapporteur on the Right to Food.

Van den Berg, J. (2016). Insect resistance management in bt maize: wild host plants of stem borers do not serve as refuges in africa. J. Econ. Entomol. 110, 221-229. doi: $10.1093 /$ jee/tow276

Van den Berg, J., Hilbeck, A., and Bøhn, T. (2013). Pest resistance to Cry1 Ab Bt maize: field resistance, contributing factors and lessons from South Africa. Crop Prot. 54, 154-160. doi: 10.1016/j.cropro.2013.08.010

van Rensburg, J. B. J. (2007). First report of field resistance by the stem borer, Busseola fusca (Fuller) to Bt-transgenic maize. South Afr. J. Plant Soil 24, 147-151. doi: 10.1080/02571862.2007.10634798

Venter, H. J., and Bøhn, T. (2016). Interactions between Bt crops and aquatic ecosystems: a review. Environ. Toxicol. Chem. 35, 2891-2902. doi: $10.1002 /$ etc. 3583

Williams, E. H., and Brower, L. (2016). A conservation concern: how many monarchs are there. News Lepidopterists Soc. 58, 90-93.

Wu, K. M., Lu, Y. H., Feng, H. Q., Jiang, Y. Y., and Zhao, J. Z. (2008). Suppression of cotton bollworm in multiple crops in china in areas with Bt toxin-containing cotton. Science 321, 1676-1678. doi: 10.1126/science.1160550

Yu, H., Li, Y., Li, X., and Wu, K. (2014). Arthropod abundance and diversity in transgenic bt soybean. Environ. Entomol. 43, 1124-1134. doi: 10.1603/ EN13337

Zalucki, M. P., Parry, H. R., and Zalucki, J. M. (2016). Movement and egg laying in monarchs: to move or not to move, that is the equation: movement and egg laying. Austral. Ecol. 41, 154-167. doi: 10.1111/aec.12285

Zeilinger, A. R., Olson, D. M., and Andow, D. A. (2016). Competitive release and outbreaks of non-target pests associated with transgenic Bt cotton. Ecol. Appl. 26, 1047-1054. doi: 10.1890/15-1314

Conflict of Interest Statement: The authors declare that the research was conducted in the absence of any commercial or financial relationships that could be construed as a potential conflict of interest.

Copyright (C) 2017 Bøhn and Lövei. This is an open-access article distributed under the terms of the Creative Commons Attribution License (CC BY). The use, distribution or reproduction in other forums is permitted, provided the original author(s) or licensor are credited and that the original publication in this journal is cited, in accordance with accepted academic practice. No use, distribution or reproduction is permitted which does not comply with these terms. 